\title{
0 jovem percurso da administração política
}

\author{
Fábio Guedes Gomes \\ Universidade Federal de Alagoas
}

\begin{abstract}
Este artigo tem a pretensão de realizar uma incursão em um "novo" campo do conhecimento que se desenvolve com muita proficuidade por um grupo de pesquisadores das áreas de administração, economia e ciências políticas. Trata-se do campo da "administração política", uma área que já demonstrou seu fôlego pelos vários trabalhos acadêmicos e científicos publicados, alguns aqui listados com o intuito de apresentá-los à comunidade de pesquisadores em geral das ciências sociais. Portanto, fazemos uma breve descrição desse caminho científico percorrido, discorrendo sobre seus principais trabalhos e discutindo a perspectiva teórica central da "administração política" e sua correlação com a economia política. Por fim, puxamos o debate para a interpretação sumária de alguns dos principais desafios que a nova divisão internacional do trabalho impõe a países periféricos como o Brasil à luz da administração e economia política.
\end{abstract}

Palavras-chave: administração política; economia política; economia brasileira contemporânea.

\section{The young road administration political}

This work aims to discuss a new field of knowledgement that is being successfully developed by a group of researchers in administration, economics and political science. It is called the "political administration", an area that has proved to be fertile through several published academic and scientifical works. Some of these works are here referred to be presented to social scientists. Therefore, we make a brief description of the development of this particular field of research, mentioning its main authors and works and discussing the main theoretical proposition of "political administration" and its correlation to the political economy. Concluding, the article discusses some of the new challenges imposed by the new International Division of Labor to nations as Brazil in light of the political administration and economy.

KEY WORDs: political administration; political economy; contemporary brazilian economy

Artigo recebido em mar. 2011 e aceito em jul. 2011. 


\section{Introdução}

Durante grande parte do século XX, desde quando o célebre trabalho de Frederick Winslow Taylor, The principles of scientific management, foi publicado, em 1911, que a área da administração como campo investigativo das ciências sociais se aperfeiçou na "arte" do "bem fazer empresarial", basicamente. Ou seja, embora a administração seja considerada uma ciência social, o desenvolvimento teórico neste campo adotou, metodologicamente, uma perspectiva excessivamente técnica com modelos instrumentais tomados como condições sine qua non da essencialidade no exercício de fazer ciência. O que deveria ser um meio para se alcançar maiores poderes explicativos da realidade, que circunda as atividades e comportamento administrativo, tornou-se um fim em si mesmo e, por isso, a produção na área tem sofrido de um alto nível de vulgarização, com seu poder científico ao longo do tempo muito efêmero. Por sua vez, as finalidades do fazer ciência em administração quase sempre se mediocrizam e se objetivam no "como gerenciar" os negócios, na operacionalidade empresarial e na interpretação do comportamento dos indivíduos no âmbito das organizações (Gomes, 2011:179).

É quase impossível encontrar nos cursos de graduação em administração geral disciplinas voltadas para a história e a filosofia. Quando, por exemplo, trabalha-se o fenômeno do fordismo, invariavelmente o aluno é forçado a entender esse processo como um instrumento, uma mera maneira de se organizar a produção em seus elementos operacionais. A perspectiva histórica e seu contexto dificilmente são apreendidos na universidade pelos alunos. O que restava de teoria social, nas origens da formação da ciência da administração, desapareceu velozmente depois da Segunda Guerra Mundial, e esse campo do conhecimento reduziu-se ao tecnicismo dominado pelos manuais a-históricos, acríticos e destituídos de sujeitos com teorizações vulgares e efêmeras. ${ }^{1}$ Boa parte da formação dos alunos nesse campo se desenvolve, infelizmente, ancorada nessa tradição manualesca.

Evidentemente que outros espaços de fazer ciência da administração surgiram nas últimas duas décadas, pelo menos. Isto de certa maneira vem "furando o cerco" da hegemonia do mainstream, principalmente de origem anglo-saxã. É crescente a consciência política e científica de que os fenômenos sociais, a dinâmica econômica, com manifestações de crises periódicas, e a dinâmica ambiental, exigem, também, da ciência da administração uma capacidade de respostas, científica e técnica, para que a humanidade enfrente os desafios impostos pela degradação social e da natureza que o regime de produção continua a impor.

É com essa preocupação que tem se desenvolvido na Bahia, especialmente na Escola de Administração da Universidade Federal (EA/UFBA), uma série de trabalhos resultantes de pesquisas e reflexões que procuram retomar, ou, digamos, reconstruir o caráter social da ciên-

\footnotetext{
${ }^{1}$ Tecendo uma crítica a J. B. Say e James Mill em uma das notas de rodapé de $O$ capital, Marx fez o seguinte comentário: "Em nenhuma outra ciência, além da economia política, predomina tanta pretensão fundada em vulgaridades elementares". Certamente o velho mouro, como era apelidado, mudaria de ideia se chegasse a ver o desenvolvimento futuro da chamada ciência da administração, quando esta se especializou a partir de contribuições dos economistas marginalistas e engenheiros industriais, após a Primeira Guerra Mundial (Gomes, 2011:179).
} 
cia da administração. Isto significa relacionar essa ciência novamente às preocupações da teoria social crítica. Esse movimento denominado "administração política" objetiva ultrapassar os horizontes limitados de investigação que dominam a área de conhecimento, extrapolando, também, os limites impostos pela incapacidade, ou desinteresse, da ciência econômica (economics) contemporânea de trabalhar em uma perspectiva mais abrangente e interdisciplinar.

A expressão administração política pode soar muito estranha aos ouvidos e mentes dos que se defrontam pela primeira vez com ela. Que dirá os estudiosos da economia política, por exemplo, tão vaidosos de que dominam a interpretação da verdadeira essência dos fenômenos reais. Mas, o próprio Marx alertou para os problemas de se iniciar uma nova maneira de estudo em qualquer área do conhecimento, quando prefaciou na primeira edição de $O$ capital: "Todo começo é difícil: isso vale para qualquer ciência".

Então, neste artigo, buscamos mostrar essa nova perspectiva analítica, apresentando, inicialmente, fatos estilizados sobre o avanço da área. Nas partes em seguida, discute-se a perspectiva metodológico-teórica da administração política, tomando por base os principais trabalhos publicados sobre o assunto e sua definição geral. Por fim, realizamos uma breve reflexão sobre a importância da admistração política para a compreensão, juntamente com a economia política, do movimento mais recente da economia brasileira e mundial.

\section{Os largos passos da "administração política"}

A preocupação de compreender melhor o campo de estudos da administração, em uma sociedade marcada pelas contradições do modo de produção capitalista, tem sido uma das principais atividades de um grupo de pesquisadores-acadêmicos vinculados à Escola de Administração da Universidade Federal da Bahia (UFBA). Desde meados da década de 1990 essa discussão vem se arrastando e ganhando corpo. Primeiro, desenvolveu-se um conteúdo epistemológico e metodológico, a partir da releitura de alguns autores clássicos da administração e economia política. Alguns trabalhos enveredaram para a compreensão dos fenômenos da realidade socioeconômica, institucional e organizacional, com a necessidade de definição do método de abordagem em que se misturam elementos captados da própria administração, do ponto de vista mais heterodoxo ${ }^{2}$ e da economia política clássica e keynesiana.

Os trabalhos pioneiros no Brasil que reconhecem a administração política como um campo de conhecimento foram publicados no início da década de 1990. O "pontapé inicial" foi um artigo publicado, em 1993, pela Revista de Administração Pública da Fundação Getulio Vargas (FGV), "A administração política brasileira”, dos professores Reginaldo Souza Santos e Elisabeth Matos Ribeiro. Nesse artigo, os autores buscam revelar as contradições das mudanças que estavam em curso no país, a partir de uma avaliação das mudanças econômicas e

\footnotetext{
${ }^{2}$ Deixando de se concentrar, demasiadamente, nos elementos instrumentais, técnicos e racionais, e reforçando a natureza e origem da ciência da administração como um campo das ciências sociais e humanas.
} 
políticas, tendo como eixo principal o Estado e suas relações com a sociedade, no contexto de ampliação dos espaços de dominação ideológica e política neoliberal.

Quase 10 anos após, foi publicado, no mesmo periódico, o texto "Em busca da apreensão de um conceito para a administração política", no qual Santos buscava aprofundar a pesquisa epistemológica, abordando o tema da "gestão" como o eixo fundamental para as preocupações da ciência administrativa. Três anos depois, em 2004, foi publicado, pela prestigiosa editora Hucitec, o livro Administração política como campo do conhecimento, com uma série de artigos de colaboradores que se engajaram na discussão.

Um grande passo na divulgação e na ampliação do espaço da discussão sobre a administração política foi dado com o lançamento, em 2008, da Revista Brasileira de Administração Política (Rebap). Em uma parceria realizada entre a Escola de Administração da UFBA e a editora Hucitec, os pesquisadores, professores e interessados na temática encontraram um ambiente de exposição de seus trabalhos e de reflexões sobre temas que abordam a área específica. ${ }^{3} \mathrm{~A}$ produção tem sido tão profícua que a Rebap já se encontra em seu quinto número, iniciando o processo de reconhecimento pela Capes para inserção no sistema Qualis.

A discussão e o desenvolvimento do campo da administração política não se encerram por aqui. No Núcleo de Pós-Graduação em Administração (NPGA) da UFBA, algumas dissertações de mestrado e trabalhos de doutoramento já foram produzidos abordando a temática ou tangenciando sua discussão. Ademais, anualmente, na mesma instituição, é realizado um grande seminário que já se encontra em sua quarta edição, com crescente participação de público e engajamento de pesquisadores e alunos. A criação do prêmio João Ubaldo Ribeiro, para as melhores monografias, dissertações de mestrado e teses de doutorado em administração política do país, merece destaque como um incentivo à produção científica na área e um reconhecimento ao esforço envidado.

Em 2010, na aprazível cidade de Garanhuns, localizada no agreste pernambucano, foi realizado um grande seminário para discutir a importância e o papel da administração política na interpretação e reflexão sobre os desafios da sociedade brasileira e seus principais problemas. $\mathrm{O}$ evento foi destinado aos pesquisadores que vêm se engajando no campo investigativo. A presença de professores de vários centros de ensino e pesquisa do país demonstrou a relevância do evento e o interesse cada vez mais abrangente na discussão. No encontro, foi selada uma parceria profícua entre NPGA/UFBA, Escola Brasileira de Administração Pública (Ebape) da FGV e Escola de Administração de Empresas de São Paulo (Eaesp/FGV), visando dar abrangência ao prêmio João Ubaldo e formar uma rede mais ampla de pesquisadores.

3 Os trabalhos seminais são: Ribeiro (2004), Vidal (2008), Caribé (2008), Cristaldo e Pereira (2008), Pedrão (2008, 2009), Santos (2008), Oliveira (2008), Castro et al. (2009), Santos, Ribeiro e Chagas (2009), Cano (2009), Craide et al. (2009), Oliveira e Santana (2009) e Araújo e Araújo (2009). 


\section{Apreendendo sobre "administração política"}

Santos e Ribeiro, em A administração política brasileira (1993), procuram analisar as transformações na vida política e econômica brasileira à luz do movimento de continuidade do desenvolvimento capitalista no país, nos últimos 25 anos do século XX. O objetivo central é compreender as mudanças na ossatura estatal brasileira que acompanham as próprias transformações do modo de produção capitalista.

Como os próprios autores demonstram, há uma intensa e profunda modificação, especialmente no quadro das políticas públicas, em virtude do novo marco de relacionamentos entre Estado e capital, instituído a partir da década de 1980. Para compreender melhor esse movimento, o trabalho remete à formação do capitalismo urbano-industrial, que toma impulso a partir de 1930, e vai transformando as estruturas políticas do Estado. Com isso, o texto se inicia com uma contextualização da evolução, desenvolvimento e reformas das instituições estatais no capitalismo periférico e suas relações orgânicas com a sociedade em uma escala de tempo. Santos e Ribeiro (1993:106) definem primariamente o que poderia significar administração política: "a forma pela qual o Estado se organiza e se estrutura para gerir o processo das relações sociais de produção".

Para se organizar e construir todo um arcabouço institucional como resposta aos novos imperativos do sistema econômico emergente em bases nacionais, o Estado não poderia prescindir dos elementos de planejamento, execução e gestão dos recursos alocados e sua aplicabilidade dentro dos objetivos das políticas públicas. Com isso, os autores precisam a importância da "administração política" como campo do conhecimento, o "como fazer" e "produzir" a interação do Estado com a sociedade, do ente político com o econômico e social, e vice-versa.

A preocupação dos autores naquele texto inaugural foi desenvolver os elementos conceituais que poderiam dar suporte ao conceito de administração política. A partir da valorização da "gestão" como categoria essencial da administração, o objeto de estudo da administração como campo do conhecimento foi se apresentando naturalmente. Nesse sentido, então, o que interessava era compreender a gestão estatal e a gestão das relações entre o ente público e a sociedade. Essa discussão foi naturalmente valorizada em razão de o capitalismo tardio periférico, como no caso brasileiro, ter se desenvolvido, essencialmente, com a força estatal de intervenção e na criação das estruturas econômicas e políticas essenciais aos desafios do desenvolvimento industrial.

Interessante observar que Wilson Cano, em seu clássico livro didático Introdução à economia, nos capítulos que dedica à formação dos sistemas econômicos, enfatiza que antes de se produzir economicamente é necessário "organizar" o sistema econômico. Ou seja, com objetivo de empregar racionalmente as técnicas, os recursos materiais e humanos, o desafio das sociedades é a imprescindível organização da produção. ${ }^{4}$ Não seria exagero dizer que

\footnotetext{
${ }^{4}$ É importante registrar que Celso Furtado, num texto intitulado "Aventuras de um economista brasileiro", escrito originalmente para um número comemorativo da International Social Sciences Journal, a pedido da Unesco, em
} 
esse desafio foi enfrentado pelo Brasil, na primeira metade do século XX, exclusivamente pelo Estado nacional. Não se deve acreditar que a iniciativa de desenvolvimento das forças produtivas no país tenha se dado pela espontaneidade dos mercados e iniciativa privados no período considerado.

Entretanto, é evidente que o modelo de desenvolvimento econômico brasileiro, entre 1930 e final da década de 1970, apresentou problemas tanto de ordem interna ao próprio modelo, como em consequência das mudanças no rumo das relações de poder internacional e na economia mundial. A partir da década de 1980, com a crise da dívida externa e o fim do regime ditatorial no Brasil, as relações econômicas internas entre o Estado e a sociedade, construídas no passado, rapidamente deterioram-se. É esse processo que Santos e Ribeiro (1993) buscam compreender à luz do desenvolvimento do conceito de administração. Este, portanto, já se encontra implícito na análise das transformações estruturais que o capitalismo periférico brasileiro iniciava e que resultaram em mudanças nos eixos de relacionamento entre o Estado e seu padrão de intervenção econômica e social. Na verdade, os autores deixam claro que a década de 1980 foi marcada pela mudança de trajetória no padrão de "gestão" das relações sociais, do ponto de vista institucional, e os novos instrumentos e objetivos da intervenção estatal que se impuseram na base do avanço das forças políticas e econômicas no país.

Os autores, portanto, tiveram o mérito de romper com a hegemonia das análises economicistas e da crítica da economia política. Avaliaram a perspectiva histórica com um olhar que resgata a importância da administração como campo da ciência social também preocupada em construir a crítica de seu ponto de vista, ou melhor, do ponto de vista da administração política. Uma crítica que se debruça sobre os aspectos essenciais da gestão das relações em uma sociedade capitalista periférica e subalterna no jogo de poder internacional. Portanto, estava dado o "pontapé inicial" do longo caminho metodológico-conceitual com a finalidade de desenvolver o conceito de administração política com base nas transformações que afligiam, sobretudo, o Estado, as relações de produção e o processo de acumulação.

O conceito de administração política procura dar conta das novas condições impostas pelas mudanças estruturais no processo de acumulação capitalista que englobou a economia brasileira, nos anos 1980, e foi remodelando, gradativamente, as relações de produção e de

1972, declara que uma das origens de seus fundamentos reside nos estudos que iniciou das organizações, e a perspectiva de que essas estruturas só poderiam funcionar adequadamente através das técnicas de planejamento. Foi com a leitura de Man and society in age of reconstruction, de Karl Mannheim, que Furtado compreendeu que o planejamento poderia ser uma técnica social "de importância muito maior, a qual permitia elevar o nível de racionalidade das decisões que comandam complexos processos sociais, evitando-se que surjam processos cumulativos e não reversíveis em direções indesejáveis". E assim ele conclui: "Fixou-se, assim, no meu espírito a ideia de que o homem pode atuar racionalmente sobre a História". Depois observa que seus estudos de organização o levaram ao planejamento e este à economia. Em suas palavras: "cheguei ao estudo da economia por dois caminhos distintos: a história e a organização. Os dois enfoques levaram a uma visão global, a macroeconômica". Então, podemos deduzir que o entendimento dos fenômenos e dinâmica do processo econômico de criação e distribuição de riquezas enseja possibilidades de a sociedade conduzir as relações sociais através, justamente, daquilo que se pode denominar de administração política (Furtado, 1997:17). 
organização e gestão institucional. Mas antes de chegarem a essa década, os autores procuraram percorrer um longo período histórico com intuito de demonstrarem que o conceito é apropriado para estabelecer análises de outros momentos históricos e diferentes modos de produção.

Para os autores, na década de 1980 foi definido um novo modelo de gestão do Estado, ou melhor, uma nova administração política brasileira, porque a crise capitalista engendrou correlações de poder diferentes das estabelecidas no passado. A crise de 1930 marcou a passagem do poder da oligarquia agrário-exportadora para a burguesia urbano-industrial. Aquela já não conseguia mais gerir o modelo de desenvolvimento brasileiro com base em uma economia produtora de bens primários para exportação. As brechas abertas pelas sucessivas crises cambiais, em razão das dificuldades de penetração das exportações no mercado internacional, foram sendo preenchidas por uma nova elite, com novos propósitos e uma ideologia de desenvolvimento econômico distinta.

Ao se inaugurar a década de 1980, a exaustão do modelo de desenvolvimento por substituição de importações e as restrições do capitalismo internacional definiram novos interesses econômicos. Ao longo do tempo, esses interesses foram se cristalizando e abrindo espaço para o surgimento de novos grupos hegemônicos, apontando as deficiências dos modelos de desenvolvimento anteriores e propondo novas alternativas.

Como em um ciclo, os novos grupos ascenderam na hierarquia de poder efetivamente, a partir de 1994, como representantes de uma nova ordem econômica, agora internacionalizada. Eram os verdadeiros representantes da globalização como a paranoia necessária à remoção dos entraves ao crescimento econômico. Entre eles, destacam-se as altas finanças (os proprietários e responsáveis pela gestão da riqueza líquida em suas diversas formas de ativos, principalmente financeiros); os poucos grandes grupos econômicos e de produtores agregados no chamado agrobusiness; o empresariado exportador de commodities industriais; os meios de comunicação; e, por fim, a classe média conservadora ascendente, afoita pelo consumo desenfreado.

A hierarquia de poder foi redefinida. Com ela, as relações de produção e os grupos econômicos hegemônicos. Em termos práticos, a sociedade brasileira aceitou, passivamente, um modelo de desenvolvimento econômico com base nos ideários neoliberais do capitalismo monopolista globalizado. E as linhas de ação eram: abertura econômica, liberalização financeira, reforma do Estado e novas linhas de ação do setor público, controle monetário, equilíbrio fiscal. O turbo capitalismo internacionalizado construiu/destruiu/redefiniu organizações, empresas, instituições, suas formas de gestão, capacidade produtiva e linhas de ação.

Enfim, Santos e Ribeiro (1993) não chegam a definir, explicitamente, o conceito de administração política. Essa clareza ficaria para os trabalhos posteriores, mesmo porque os autores estão iniciando o trabalho de pesquisa nesse campo. No entanto, o método de análise já demonstra, claramente, uma forma diferente de olhar o processo de desenvolvimento econômico brasileiro, em que os limites entre a economia política crítica e a administração política ainda não estão definidos. Embora esse seja um problema aceitável, pela razão já apontada, é importante ficar claro que a preocupação dos autores é procurar compreender como a 
produção capitalista no Brasil se organiza e passa por modificações, reformas ou mudanças, seja lá qual for a categoria que compreenda o processo histórico de construção e reconstrução das relações entre o Estado e a economia capitalista periférica, e a gestão dessas relações no contexto dos conflitos de classe (inter e intraclasse).

\section{0 conceito de "administração política"}

No texto Em busca da apreensão de um conceito para a administração política (2001), Santos detém-se, com mais acuidade, nos aspectos epistemológicos da administração política. Nele, o conceito vai ficando mais claro, por um lado, e, por outro, suscita algumas preocupações no que se refere a sua abrangência analítica do ponto de vista metodológico. Inicialmente, o autor dialoga com alguns clássicos da administração, procurando subsídios que deem suporte a seu desenvolvimento. Inicia-se discutindo um dos temas mais caros à administração: ser ou não ser uma ciência.

Depois de comentar as principais obras de Taylor, Waldo, Dimock, Simon e Guerreiros Ramos, nosso autor conclui que nessas referências não se encontra uma contribuição relevante para que a administração alcance o status de ciência. Para ele, o objeto e o método nessa disciplina se apresentam de maneiras distintas entre os autores analisados, diferentemente de outros campos da ciência que têm maior clareza sobre seus objetivos e métodos. Conforme Santos (2001:54), "não se conhece qualquer discussão dirigida acerca do objeto e do método no campo da administração, mas alguns autores têm a mais absoluta certeza de que administração é uma ciência". Mais adiante, reafirma essa conclusão ao dizer que a administração é um campo disciplinar ainda indefinido no estágio atual de evolução das ideias científicas (Santos, 2001:61).

O objetivo de Santos é, justamente, demonstrar como o conceito de administração política pode ser um instrumento analítico que possa contribuir para ampliar o escopo de estudos científicos no campo da administração, tentando, com isso, aproximar-se de uma definição mais clara de seu objeto científico e desenvolvimento metodológico. Santos tem a clara percepção de que o objeto da administração é a gestão e não a organização. Ao comentar que Guerreiros Ramos critica a teoria das organizações pelo seu forte componente de racionalidade formal/instrumental, centrado nos interesses mercadológicos, Santos (2001:60) afirma o seguinte:

Ora, quando Guerreiro Ramos formulou esse pensamento em direção à fundação de uma nova ciência das organizações, imaginava-se que fosse romper em definitivo com o velho paradigma e efetivamente fazer da administração um novo campo disciplinar, que até aquele momento ela não fora pelo simples fato de não ter um objeto de estudo e um método próprios. Esse rompimento não ocorre pelo simples fato de o autor ainda considerar que o objeto da administração é a organização. Como, no nosso modo de ver, o objeto de administração se cristaliza no conteúdo 
da gestão, então Guerreiro Ramos não constrói uma nova ciência da administração, mas simplesmente continua falando da mesma coisa utilizando-se de novas categorias analíticas.

Como ficou exposto, Santos redefine o objeto de estudo da administração como a gestão e, a partir de então, acredita que a gestão pode estar em dois campos de análise: no campo político e no campo profissional. No primeiro, a característica principal é a gestão em um espectro mais amplo, macro, que é imprescindível em diferentes modos de produção e formas organizacionais. O segundo preocupa-se com a gerência na dimensão micro, nas unidades econômicas, políticas e sociais. Para ele, portanto, "as organizações/instituições constituem os gêneros que contêm elementos essenciais do objeto da disciplina administração, elas são espaços particulares onde apenas habita o objeto" (Santos, 2001:62).

Mas uma questão ainda fica em aberto: por que a organização não deve ser o objeto de estudo da administração? Simplesmente porque, dado o grau de complexidade que envolve as relações sociais internas à organização e os vários problemas que emergem de seu interior, elas podem ser objetos de estudos de várias áreas do conhecimento. Por exemplo, o processo de intensificação de exploração capitalista, que ocorre no espaço das empresas, pode levar os trabalhadores à fadiga, estresse, acidentes de trabalho etc., que são tratados pela ciência médica. As rotinas, e até mesmo o exercício de poder sobre os trabalhadores, podem provocar distúrbios psíquicos, analisados e amenizados pela psicologia e/ou psiquiatria.

A ideia, portanto, é evidenciar que as organizações são ambientes multidisciplinares e interdisciplinares de estudos. As organizações e seus problemas, portanto, são objetos também de outras ciências, tirando, dessa feita, o privilégio da administração no campo do estudo das organizações. Assim, "cabe à administração estruturar um modelo de gestão viabilizador do objetivo da organização. Portanto, a gestão é apenas um dos conteúdos que dão institucionalidade e essência às organizações" (Santos, 2001:63).

A psicologia, a medicina, a economia, a engenharia, a ciência política, a sociologia etc. podem se servir, também, das organizações como objeto de pesquisa. Por outro lado, a gestão, segundo Santos, é o campo específico da administração e lhe pode conduzir ao status de ciência se, nesse ambiente, as pesquisas forem dirigidas para melhor definição científica do objeto de estudo. Além disso, para que isso aconteça, Santos enfatiza que a gestão tem de fazer parte de um espaço maior, ultrapassando os limites das organizações.

No campo político, trata-se de um objeto de estudo bem delimitado, e a preocupação de Santos é concentrar-se e aplicar o método-analítico da administração política para compreender como se desenvolve a dinâmica da gestão das relações sociais. Incluindo, obviamente, o Estado como ator imprescindível na condução dos destinos econômicos e da produção em um país. Sua preocupação é não analisar o ambiente micro, uma organização simples, tipicamente capitalista. Mas o Estado, o ambiente macro, no qual se cristalizam as forças internas conflitantes da sociedade e se desenvolveram pelas relações sociais de produção. É por essa razão que Santos tem por objetivo compreender e analisar as transformações pelas quais passa o Estado brasileiro, seu objeto específico de pesquisa, no que se refere à gestão pública e suas repercussões na (des)construção da nação, notadamente no período 1930-90. 
O conceito de administração política, portanto, extrapola a forma convencional com que a administração procura se definir como ciência. De qualquer maneira, contribui para ampliar o espectro de estudo e para buscar compreender a própria gestão das relações que se estabelecem em três dimensões constitutivas dos modos de produção na era moderna: sociedade, Estado e organizações privadas.

\section{A "administração política" como campo científico}

A preocupação com o ambiente "macroestrutural" é compreensível porque é nesse nível que o conceito de administração política ganha maior relevância em razão da importância que pode assumir quanto às estratégias adotadas com objetivo de construção de condições mais apropriadas da materialidade da sociedade. Ou seja, no plano "macroestrutural" é que se definem os destinos de uma sociedade, seu desenvolvimento coletivo em aspectos sumamente importantes, entre eles: a cultura, a economia, a sociabilidade e a riqueza.

No livro organizado por Santos, A administração política como campo do conhecimento (2004), o segundo capítulo direciona-se para essa preocupação. Demonstra que é o ambiente "macroestrutural" que importa, porque é nele que se define o modelo de gestão que pode ter vários propósitos, e o mais nobre é garantir as condições mínimas de desenvolvimento dos indivíduos e seu progresso material e cultural. Para Santos, a administração política deve assumir o compromisso de contribuir com a crítica, a reflexão e a proposição de políticas que atendam os requisitos necessários para a garantia de certo nível de bem-estar coletivo. A responsabilidade disso não pode ficar restrita ao papel das organizações no plano micro.

No nível "macro", a administração política (modelos de gestão) do capitalismo contemporâneo, ao contrário, segue sua linha histórica que parece desembocar numa encruzilhada para a sociedade humana: seus fins são produzir tudo o que possa incorporar um valor de troca, sem necessariamente ter alguma utilidade para a sociedade. ${ }^{5}$

Ou seja, transformar em valor monetário (preços) todos os produtos e serviços que propiciem lucros e deem continuidade ao processo de acumulação capitalista, com muito pouca preocupação com os impactos causados pelo padrão de consumo imposto.

\footnotetext{
${ }^{5}$ Em um pequeno ensaio, Meszáros (1989) alerta para os riscos que o capitalismo vem impondo à sociedade humana ao produzir mercadorias com características destrutivas ao sistema vital social. Na mesma linha de raciocínio, Campos (2001) demonstrou, criticamente, que os objetivos do capitalismo, no atual estágio de desenvolvimento das forças produtivas, têm conduzido à produção de não mercadorias, ou seja, objetos ou produtos que têm funções muito duvidosas para o progresso da humanidade. Meszáros analisa o comportamento dos gastos da economia norte-americana com indústria bélica, por exemplo. As não mercadorias, portanto, têm alto poder de destruição e não necessitam dos mercados consumidores tradicionais para sua realização. Ou melhor, sua produção não está condicionada aos imperativos da demanda nem ao ritmo da atividade econômica. A utilidade de alguns bens e serviços de consumo final produzidos pelo capitalismo, por exemplo, suscita dúvidas com relação a sua importância para o progresso social e humano.
} 
Nesse sentido, o que temos é uma administração política voltada para os interesses da base econômica sob o domínio do capital, visto que o ponto vital de todos os esforços administrativos vincula-se à transformação dos produtos e serviços em valor monetário que propicie lucros. Assim, as necessidades reais da sociedade ficam em segundo plano, subsumidas aos interesses do capital (Santos, 2004:56).

Três correntes do pensamento econômico - gerencialismo, institucionalismo e regulacionismo - são avaliadas criticamente por Santos (2004), com o intuito de saber como elas tratam o nível "macroestrutural" do ponto de vista do desenvolvimento das relações de produção e das forças econômicas com vistas ao progresso social. Como no nível "microestrutural" as organizações e suas formas de gestão são quase sempre movidas pelas perspectivas dos ganhos econômicos, esse nível pouco interessa para Santos. Nesse nível, o positivismo da economia neoclássica e a racionalidade instrumental da administração se preocupam em nutrir as estratégias de gestão com aquela perspectiva apontada, com poucas preocupações com a transformação social no plano macro. Nesse caso, a administração tem forte alinhamento genético da racionalidade instrumental e funcionalista, típica das correntes marginalistas e utilitaristas do pensamento econômico conservador.

Excluindo a perspectiva analítica de uma administração apenas voltada para os resultados econômicos das organizações capitalistas e das organizações sociais, funcionais ao desenvolvimento do sistema em sua totalidade (organizações sindicais, sociais, filantrópicas etc.), Santos busca na relação Estado/sociedade uma maneira de não se prender, criticamente, à lógica mercantil, ao mesmo tempo que tenta discutir um projeto societário mais amplo.

A compreensão dessa ruptura instrumentalista deve ser um dos fundamentos básicos dos pressupostos da administração política. Então, as interfaces entre as relações das razões instrumentais e subjetivas constituem, neste livro, um pressuposto básico da estruturação da Administração Política para privilegiar um plano nacional com fins societais de desenvolvimento humano comum (Santos, 2004:60).

Para Santos, a corrente gerencialista contribui relativamente para o amadurecimento do conceito de administração política, principalmente os estudos de James Burnham. Segundo ele:

O gerencialismo de Burnham tem algumas interfaces com as nossas preocupações a respeito da Administração Política. A sua ideia de montar um modelo de organização mundial único, a partir de dois países hegemônicos, para a eliminação de conflitos e a criação de uma sociedade única, é uma aproximação forte do nosso conceito de Administração Política, que se traduz na preocupação de construção de uma gestão das relações sociais para a elevação do grau da materialidade da humanidade (Santos, 2004:65).

Na verdade, o que Santos quer extrair das análises de Burnham é a perspectiva da gestão dentro de seu entendimento do que seja gerencialismo. Todavia, ao conceber a gestão como um fim em sim mesmo, e não como um meio para se alcançar resultados materiais em 
uma sociedade mais igualitária, não fica muito clara a importância dessa escola na contribuição do conceito da administração política.

Por outro lado, a análise de alguns trabalhos da corrente regulacionista, feita por Santos (2004), concentra-se na perspectiva da preocupação de seus autores em compreenderem o movimento de regulação do modo de produção capitalista. Com o desenvolvimento do conceito de regulação, surge implicitamente a ideia de gestão, pois ela é necessária na busca do equilíbrio entre o desenvolvimento das forças produtivas e as estruturas institucionais.

Para os regulacionistas, as crises estruturais do modo de produção capitalista decorrem de incompatibilidades entre as novas condições de produção e os arranjos institucionais que não são suficientes para adequar a sociedade àquelas condições mais avançadas produtivamente. Assim, para a Escola da Regulação, as soluções para as crises superam a perspectiva revolucionária típica do marxismo ortodoxo, pois seriam precisos novos arranjos institucionais capazes de gerir as novas condições de desenvolvimento das relações sociais de produção.

Na verdade, implicitamente, a Escola da Regulação acredita que a fonte de desequilíbrio no capitalismo contemporâneo, em última instância, é a perda de capacidade da administração política das relações de produção no contexto de profundas rupturas do "contrato social" estabelecido na ascensão e auge dos regimes de produção. E é justamente durante essas rupturas que modificações importantes vão ocorrer nas funções do Estado como eixo central das relações políticas e econômicas do sistema. Geralmente, cabe a ele buscar atenuar os conflitos inerentes às mudanças e impor novas regras de sociabilidade dentro de um novo marco de gestão adequando-as às novas características do regime de produção superior.

Para Santos (2004:68), a escola regulacionista pretende, "através da regulamentação das relações sociais de produção, um gerenciamento do capitalismo como forma de minimizar os efeitos das crises cíclicas que lhe são próprias". Reforçando essa mesma crítica, Braga (2003), num fascinante trabalho, pontua que a Escola da Regulação vê-se obrigada, contra os desejos mais caros de seus principais representantes, a aceitar a conflitualidade imanente à sociedade capitalista. E a possibilidade é de projetá-la para o futuro, compartilhando da ideia de que é possível apenas gerenciar os problemas de formas diferentes em cada momento histórico de seu desenvolvimento.

O importante nessa discussão é o papel das instituições na dinâmica de regulação do regime de produção. Para Santos (2004:72), “o fim maior da administração não se vincula à espontaneidade autoequilibrada por simples fenômenos de mercado e de concorrência. As instituições e formas estruturais são determinantes para direcionar este processo dentro de um conjunto de comportamentos coletivos e individuais".

Destarte, a gestão torna-se imprescindível como instrumento no auxílio da pactuação dos interesses divergentes e diversificados estabelecidos pelas relações sociais de produção. E, portanto, as condições de sobrevivência material da sociedade dependem das forças do Estado para estabelecer o mínimo de condições de sociabilidade, minimizar externalidades negativas causadas pela produção capitalista e compensar as perdas materiais e sociais causadas pelo processo de acumulação. 
A colocação nesses termos não implica uma defesa dos princípios institucionalistas e regulacionistas. Trata-se, apenas, de enfatizar que, de uma forma ou de outra, a gestão também perpassa o âmbito macro, ou seja, o nível das relações sociais de produção e os regimes por elas estabelecidos. Se considerarmos que a gestão tem esse grau de importância no plano macro, assim como no ambiente microeconômico, no nível das firmas e organizações, é mais fácil reconhecer o sentido em que Santos desenvolve a categoria administração política como uma concepção crítica dos modelos de gestão societais. Seja no plano das regiões, como no das nações ou das relações internacionais. E, como nesses respectivos planos a figura do ente estatal ou supraestatal é um elemento a considerar, a discussão da administração política passa irremediavelmente, também, pela compreensão das relações estabelecidas por essas instituições e o estabelecimento dos modelos de gestão. Talvez, a citação abaixo seja mais esclarecedora do que nossas palavras.

Fica evidente que a economia, particularmente a economia capitalista, é operada, de forma deliberada, por um processo gestionário. É algo como se $O$ Que Fazer (tomado aqui como a definição das quantidades) nunca pudesse se viabilizar sem $O$ Como Fazer (compreendido como os arranjos organizacionais e institucionais necessários para viabilizar a produção das quantidades demandadas). Esse é o momento em que a Economia Política caminha junto da Administração Política - portanto, é o momento em que se compreende de forma científica que a produção, a sua realização e a sua distribuição não se efetivam em termos de resultados ótimos sem uma concepção de gestão previamente estabelecida (Santos, 2004:71-72). ${ }^{6}$

A discussão avançou na perspectiva epistemológica e parte do grupo de pesquisa, coordenado por Santos, publicou, na Revista de Administração Pública (RAP), em 2009, o texto intitulado "Bases teórico-metodológicas da administração política", no qual discute, dentro do campo da economia e ciência política, vestígios de categorias que fortalecem as teses da pesquisa que procuram dar suporte ao reforço do conceito de administração política.

Por fim, como resultado do Encontro de Garanhuns, a editora Hucitec publicou dois livros, no final de 2010, que avançam na perspectiva crítica da administração política. O primeiro deles, intitulado $A$ administração política para o desenvolvimento do Brasil, reúne um seleto grupo de textos de autores das universidades acima citadas, e outros convidados

\footnotetext{
${ }^{6}$ Furtado comentando sua pretensa arrogância em achar que o homem pode atuar racionalmente na história e conduzi-la, como posto na nota de rodapé anterior $\mathrm{n}^{\circ} 5$, faz um comentário muito especial e que é extremamente pertinente para ratificar essa citação acima, que com toda certeza seu autor desconhecia. Então aponta Furtado: "A extrema angústia intelectual que sofri nessa época [ditadura de Vargas] começou a dissipar-se quando cristalizou-se no meu espírito essa ideia de que o homem virá a ser dono de seu próprio destino numa sociedade cujas estruturas hajam sido concebidas para este fim. Aqueles que alcançam esse ponto de vista, isto é, que pensam que o homem pode conduzir a História, quase sempre já estão preparados para dar o passo seguinte, ou seja, pensar que ele deve fazê-lo. O problema que se coloca então é o de saber como fazê-lo". Observem que é justamente no campo da administração política como vem sendo discutido, que, mesmo sem trabalhar essa categoria, Furtado se preocupa com o processo civilizatório e a condução dos processos sociais. (Furtado, 1997, p. 18, grifos do autor)
} 
que refletem a preocupação com os destinos do Brasil no contexto de fortes assimetrias de poder nas relações econômicas internacionais e os desafios da economia e do sistema nacional diante da remodelagem do padrão de desenvolvimento que o país vem enfrentando. Keynes e a proposta de administração política para o capitalismo, de autoria de Reginaldo Souza Santos, o segundo livro publicado, contém uma crítica contundente à visão de externalidade do Estado no contexto das críticas do modelo neoliberal de inserção internacional. Em razão da grave crise econômica mundial enfrentada pelos EUA e irradiada para o resto do mundo, a partir de 2007, a tese do autor concentra-se no argumento de que o Estado tem um papel preponderante na condução do sistema capitalista como o próprio capital encarnado a apontar e dirigir o sistema. Ademais, este livro guarda muitas semelhanças com as ideias de Robert Skidelsky, um dos maiores biógrafos de John Maynard Keynes, expostas em seu mais recente livro - Keynes, o regresso do mestre (2010) — sobre a importância das teses do economista britânico a respeito das instabilidades sistêmicas do capitalismo e a necessidade do uso da racionalidade econômica para administrar os ciclos de incerteza. Portanto, o que Skildesky trabalha, na perspectiva keynesiana, como gestão do processo de desenvolvimento das forças produtivas no interior do modo de produção capitalista, Souza está se referindo à proposta de Keynes para a administração política do sistema.

\section{Notas conclusivas}

No final do "Encontro da administração política para o desenvolvimento do Brasil", realizado em Garanhuns, na primeira semana de janeiro de 2010, discutiu-se e lançou-se a Carta de Garanhuns. No documento, um dos objetivos foi delimitar a preocupação da administração política com os destinos nacionais e marcar a diferença desse campo de estudos dos já tradicionais na área.

Na carta está, explicitamente, exaltado o papel da administração como uma disciplina social, "de natureza política, ideológica, propositiva de ações transformadoras da sociedade e condutoras do desenvolvimento, com um olhar transdisciplinar, crítico, histórico e cultural da dinâmica social". Nessa perspectiva, reforçou-se a preocupação da administração política de realizar a crítica dos modelos de gestão e desenvolver elementos de análise que se debrucem sobre as alternativas que possam solucionar os desafios da sociedade contemporânea.

O propósito desse Encontro, portanto, foi estimular uma ampla reflexão sobre o tema da Administração Política, entendida como possibilidades de gestão das relações sociais de produção e distribuição, contextualizadas histórica e simbolicamente, com vistas à superação dos desafios que se apresentam à Nação nesta etapa histórica de profundas desigualdades, em um mundo de radicais mudanças nas relações de poder (Santos, 2010:235).

A participação da área da administração na discussão sobre os desafios da sociedade e da economia somente tem a acrescentar à reflexão nacional. Geralmente, esse debate é 
dominado pelos economistas, em razão de a política econômica ser o tema que se sobrepõe aos demais no cenário político quando a preocupação com os modelos de crescimento e de desenvolvimento econômicos fazem parte da agenda política.

É preciso reconhecer que depois da grave crise econômica e financeira que atingiu o centro do capitalismo, os EUA, em 2007/08, houve uma mudança "relativa" na linha de política econômica que prevalecia no Brasil, desde o início da década de 2000, depois da grave crise cambial de 1999. Mais especificamente, a política fiscal passou a ser muito mais expansionista em resposta àquela crise, assumindo caráter anticíclico tradicional, com aumento dos gastos públicos e dos subsídios fiscais. Ademais, a expansão do crédito público e as transferências sociais, através dos programas sociais, colaboraram com as políticas anticíclicas para melhorar o quadro de geração de emprego, transferência de renda e redução da desigualdade social.

Entretanto, desde 1994 que na política econômica predominam os objetivos de controle e estabilidade dos preços por intermédio da dominação da política monetária, mais especificamente o manuseio da taxa de juros básica e da taxa de câmbio. Apesar da política anticíclica adotada a partir de 2009, há anos que a política econômica é conduzida pelo tripé câmbio flutuante, superávits primários e regime de metas de inflação. Assim, a definição da política de governo, de FHC a Lula, depende da discussão das possibilidades dentro do raio de manobra definido pelos objetivos da política econômica e, também, das consequências sobre esses objetivos. Apesar de a crise econômica internacional ter provocado certa inflexão no excesso de conservadorismo na política econômica, isso ainda não seria suficiente para explicar exclusivamente o bom desempenho da economia brasileira durante o segundo mandato do governo Lula, por exemplo. É preciso reconhecer o crescente dinamismo do PIB, da geração de emprego e renda com diminuição das desigualdades econômicas, caracterizada pela ascensão das classes D e E à classe C. ${ }^{7}$ No entanto, parcela desse quadro alentador se deve, também, à diminuição do grau de vulnerabilidade externa da economia brasileira, que permitiu tomar medidas mais ousadas no campo econômico sem muitas preocupações com as contas externas. Essa vulnerabilidade diminuiu em razão do forte dinamismo da economia chinesa, que tem ampliado fortemente a demanda pelas importações de commodities primárias do Brasil.

É consenso que o longo processo histórico, que se arrasta desde a década de 1980, de participação crescente da economia chinesa na economia internacional, vem redefinindo a divisão internacional do trabalho. Isso acarreta dois problemas para a economia brasileira com sinais inversos. O positivo é, justamente, colaborar com a redução do grau de vulnerabilidade externa do país em razão do crescimento extraordinário de nossas exportações de bens primários. Por outro lado, o fator negativo é que a política econômica sustentada naquele tripé promove a valorização cambial que tem reduzido as possibilidades de crescimento industrial mais robusto com a colaboração do desenvolvimento tecnológico do país. Nesse sentido, as evidências de reprimarização da nossa pauta exportadora e de desindustrialização, em alguns setores da economia, lançam um grande desafio para o futuro do país e sobre sua inserção

\footnotetext{
${ }^{7}$ Sobre o assunto ver Espinheira, Gomes e Gomes (2011).
} 
internacional, podendo reduzir sua participação na economia mundial a características já experimentadas no passado. ${ }^{8}$

Esse debate, então, não deveria ficar ciscunscrito ao mundo da economia. As relações estabelecidas entre a política econômica de governo, o contexto internacional e a ideologia e as forças políticas e econômicas, que dão sustentação ao modelo de crescimento e desenvolvimento econômico, influenciam, decisivamente, as políticas públicas e condições de vida de uma parte considerável da sociedade brasileira.

Por essas razões que o campo da administração, e a "administração política" como linha de conhecimento, deve se preocupar com essas discussões; elas envolvem uma tipologia de "gestão" das grandes questões nacionais, que perpassa também por um modelo de "gestão" do Estado, principalmente da política econômica. A capacidade de centralização da política econômica, no sentido de definição e redefinição das fontes e do uso dos recursos financeiros necessários para viabilizar as diretrizes, ações, programas e projetos das demais políticas públicas, promove sua própria "gestão" à condição de supremacia. Nesse caso, a administração política tem o papel imprescindível de fazer a crítica da influência do econômico sobre o político, e na definição da agenda do país e da gestão da sociedade.

\section{Referências}

ARAÚJO, S.V.; ARAÚJO, J.G.R. Da racionalidade à materialidade: razão e prática da administração política. Revista Brasileira de Administração Política, São Paulo, v. 2, n. 1, abr. 2009.

BRAGA, Ruy. A nostalgia do fordismo: modernização e crise na teoria da sociedade salarial. São Paulo: Xamã, 2003.

CAMPOS, Lauro. A crise completa: a economia política do não. São Paulo: Boitempo, 2001.

CANO, Wilson. Brasil: é possível uma reconstrução do Estado para o desenvolvimento? Revista Brasileira de Administração Política, São Paulo, v. 2, n. 1, abr. 2009.

CANO, Wilson. Introdução à economia: uma abordagem crítica. São Paulo: Unesp, 2007.

CANO, Wilson. América Latina: notas sobre a crise atual. Revista Economia e Sociedade, v. 18, n. 3 , p. 603-621, dez. 2009.

CARIBÉ, Daniel. Ciência ou ideologia? A constituição do campo da administração política. Revista Brasileira de Administração Política, São Paulo, v. 1, n. 1, out. 2008.

CASTRO, A.A.; BURGOS, F.; DAMÁSIO, M.V.; GUILLAUMON, S.; BRAGA, T. Contribuições de Lênin e Schumpeter para a história da administração: reflexões sobre um conceito em construção: administração política. Revista Brasileira de Administração Política, São Paulo, v. 2, n. 2, out. 2009.

\footnotetext{
${ }^{8}$ Sobre esse assunto o debate é muito forte atualmente. Ver os trabalhos de Nassif (2008) e Cano (2009).
} 
CRAIDE, A.; SACRAMENTO, A.R.; RIBEIRO, D. de A.; SILVA, L.P. da. Administração política versus administração profissional: analisando o campo de conhecimento de ensino superior de administração. Revista Brasileira de Administração Política, São Paulo, v. 2, n. 1, abr. 2009.

CRISTALDO, R.C.; PEREIRA, C.M. A administração política e a gestão do modo de produção: processos gestoriais, da organização produtiva do trabalho à economia-mundo capitalista. Revista Brasileira de Administração Política, São Paulo, v. 1, n. 1, out. 2008.

ESPINHEIRA, Gey; GOMES, Fábio Guedes; GOMES, Álvaro. O livre pensamento dos fóruns sociais: teoria social crítica e economia política contemporânea. São Paulo: Anita Garibaldi, 2011.

FURTADO, Celso. Obra autobiográfica. Tomo II. São Paulo: Paz e Terra, 1997.

GOMES, Fábio Guedes. Crítica da administração política: o necessário combate às vulgaridades. In: SANTOS, Reginaldo Souza. Keynes e a proposta de administração política do capitalismo: uma crítica aos pressupostos da externalidade do Estado e da crise fiscal. São Paulo: Hucitec, 2011. Posfácio.

MESZÁROS, István. Produção destrutiva e Estado capitalista. São Paulo: Ensaio, 1989.

MOREIRA, F.S. Administradores políticos enquanto classe: um projeto de pesquisa. Revista Brasileira de Administração Política, São Paulo, v. 1, n. 1, out. 2008.

NASSIF, A. Há evidências de desindustralização no Brasil? Revista de Economia Política, v. 28, n. 1, p. 72-96, 2008.

OLIVEIRA, Francisco Correia de. Administração pública e teoria da administração: contribuições históricas de autores brasileiros. Revista Brasileira de Administração Política, São Paulo, v. 1, n. 1, out. 2008.

OLIVEIRA, Ivan T.M.; SANTANA, Weslei G.P. A administração política do comércio internacional: do livre comércio ao comércio estratégico administrado. Revista Brasileira de Administração Política, São Paulo, v. 2, n. 1, abr. 2009.

PEDRÃO, Fernando Cardoso. Administrar processos conflitivos no capitalismo tardio. Revista Brasileira de Administração Política, São Paulo, v. 2, n. 2, out. 2009.

PEDRÃO, Fernando Cardoso. A administração política de Rômulo Almeida: pensar (e viver) o futuro. Revista Brasileira de Administração Política, São Paulo, v. 1, n. 1, out. 2008.

RIBEIRO, Elizabeth Matos. Revisitando o conceito de administração política. In: SANTOS, R.S. A administração política como campo do conhecimento. São Paulo: Hucitec, 2004.

SANTOS, Reginaldo Souza; RIBEIRO, Elizabeth Matos. A administração política brasileira. Revista de Administração Pública, Rio de Janeiro, v. 4, jul./ago. 1993.

SANTOS, Reginaldo Souza. Em busca da apreensão de um conceito para a administração política. Revista de Administração Pública, Rio de Janeiro, v. 5, set./out. 2001.

SANTOS, Reginaldo Souza (Org.). A administração política como campo do conhecimento. São Paulo: Hucitec, 2004. 
SANTOS, Reginaldo Souza. Keynes e a proposta de administração política do capitalismo. Revista Brasileira de Administração Política, São Paulo, v. 1, n. 1, out. 2008.

SANTOS, Reginaldo Souza (Org.). Administração política para o desenvolvimento do Brasil. São Paulo: Hucitec, 2010.

SANTOS, Reginaldo Souza. Keynes e a proposta de administração política do capitalismo: uma crítica aos pressupostos da externalidade do Estado e da crise fiscal. São Paulo: Hucitec, 2011.

SANTOS, Reginaldo Souza; RIBEIRO, Elizabeth Matos; CHAGAS, Thiago. Bases teórico-metodológicas da administração política. Revista de Administração Pública, Rio de Janeiro, v. 43, n. 4, jul./ago. 2009.

SKIDELSKY, Robert. Keynes, o regresso do mestre. Lisboa: Texto Editores, 2010.

VIDAL, Francisco C. Barqueiro. Para o acervo de raridades: uma discussão epistemológica no âmbito da administração política. Revista Brasileira de Administração Política, São Paulo, v. 1, n. 1, out. 2008.

Fábio Guedes Gomes é professor da graduação e do Programa de Mestrado em Economia da Faculdade de Economia, Administração e Contabilidade (Feac) da Universidade Federal de Alagoas (Ufal). E-mail: fbgg30@yahoo.com.br. 